\title{
Ueber die Einwirkung von Trypsin auf Leim. \\ Yon
}

Dr. Friedrieh Reich-Herzberge.

(Aus der chemischen Abtheilung des physiologischen Institats zu Berlin.)

(Der Redaction zugegangen am 28. October 1901.)

In einer älteren Abhandlung, die sich mit der Verdauungswirkung des Trypsins beschäftigt, macht $K$ ühne ${ }^{1}$ ) die Angabe, dass Gelatine unter der Einwirkung des Trypsins weder Leucin noch Glycocoll liefert. Weitere Untersuchungen über diesen Punkt scheinen nicht gemacht zu sein, wenigstens findet sich in der Litteratur keine Angabe. Die. Lehrbücher von Neumeister und Hammarsten haben den Befund Kühne's aufgenommen, doch lässt der Wortlaut einen gewissen Zweifel an seiner Richtigkeit erkennen. Und in der That muss es auffallend erscheinen, dass das Glutin, welches durch Säuren, Alkalien, Mikroorganismen ebenso wie das Eiweiss unter Bildung von Aminosäuren gespalten wird, sich dem Trypsin gegenüber, abweichend vom Eiweiss, so widerstandsfähig erweisen soll.

Auf Anregung von Herrn Prof. Thierfelder habe ich unternommen, diese Frage einer erneuten Prüfung zu unterziehen.

Als Material diente die reinste Gelatine des Handels. Sie wurde entweder direkt benutzt oder nachdem sie mehrere Tage mit Wasser ausgezogen war. Das Trypsin war ein Präparat von Merck, welches Eiweiss mit Leichtigkeit bis zur Bildung krystallinischer Produkte zersetzte. Zur Verhinderung der Fäulniss wurde reichlich Chloroform zugefügt. Für jeden

1) Verhandl. des naturhist. med. Vereins zu Heidelberg. N. F. Band I S. $198,1877$.

Hoppe-Seyler's Zeitschrift f. physiol. Chemie: XXXIV. 
Versuch nahm ich mindestens $50 \mathrm{~g}$ Gelatine. Die Versuchsbedingungen wurden vielfach gewechselt: es kamen 10\%-, 5\%-, $2 \%$ ige Gelatinelösungen mit Zusätzen von Natriumcarbonat, die zwischen 0,2 und $1 \%$ schwankten, zur Verwendung. Manche Versuche erhielten keinen Sodazusatz. In einigen Fällen wurde Borax resp. Galle, Mittel, denen eine Verstärkung der Trypsinwirkung zugeschrieben wird, zugefügt. Die Temperatur betrug $37^{\circ}$. Die Versuchsdauer schwankte zwischen 16 Tagen und 3 Monaten.

Die Untersuchung der verdauten Flüssigkeiten anf Aminosäuren geschaho in der bekannten Weise. Die klare, von einem geringen Bodensatze anorganischer Bestandtheile abgegossene Lösung wurde mit Schwefelsäure bis zu $5 \%$ versetzt, mit Phosphorwolframsäure ausgefällt, das Filtrat mit Baryt alkalisch gemacht, die filtrirte Flüssigkeit mit Schwefelsäure neutralisirt und nach abermaliger Filtration bis zum beginnenden Syrup eingedampft. Beim Erkalten schied sich in allen Fällen eine Krystallhaut aus, die ebenso wie der sich bildende Bodensatz aus mikroskopischen Kugeln bestand. Durch Umkrystallisiren aus Wasser und ammoniakalischem Alkohol liessen sie sich einigermassen isoliren. Die Menge war aber so gering, dass zur Reinigung und genaueren Prüfung die Krystallisationen aus mehreren Portionen vereinigt werden mussten.

Das reine Präparat zeigte die Eigenschaften des Leucins. Es krystallisirte aus Wasser in dünnen Blättchen, sublimirte in weissen; wolligen Flocken unter Entwickelung des charakteristischen Geruchs und schmolz im zugeschmolzenen Röhrchen bei $285^{\circ}$ unter Zersetzung. Die Kupferverbindung schied sich aus Wasser in blassblauen, zusammengeschobenen Tafeln ab und entsprach der Formel $\left(\mathrm{C}_{6} \mathrm{H}_{12} \mathrm{NO}_{2}\right)_{2}$ Cu. Gef. $19,80 \% \mathrm{Cu}$, ber. $19,64 \% \mathrm{Cu}$.

Ein augenfälliger Einfluss von Seiten des Alkalescenzgrades, der.Verdünnung, der Versuchsdauer, der Anwesenheit von Galle oder Borax auf die Menge des gebildeten Leucins liess sich nicht mit Sicherheit constatiren; allerdings war, wie gesagt, die absolute Menge stets eine sehr geringe, in keinem Fall dürften mehr als einige Zehntelgramm gebildet sein. Unter 
diesen Verhältnissen wurde davon abgesehen, noch auf andere Amino- und Diaminosäuren zu prüfen, die jedenfalls auch, aber ebenfalls in sehr geringer Menge, entstanden sein werden.

Um dem Einwand, dass das Leucin aus dem Trypsinpräparat stamme, oder unter dem Einfluss der Soda allein aus Gelatine gebildet sein könne, zu begegnen, wurden gleichzeitig mit den erwähnten Versuchen solche angestellt, in denen einerseits Trypsin und andererseits Gelatine mit verschieden starken Sodalösungen kürzere und längere Zeit der Bruttemperatur ausgesetzt wurden. In keinem Fall liess sich Leucin isoliren. Gegen den Einwand, dass das Leucin aus der Gelatine beigemengtem Eiweiss herrührte, spricht die Thatsache, dass es niemals gelang, Tyrosin nachzuweisen.

Aus dieser Untersuchung ergibt sich also, dass die Angabe Kühne's sich insofern bestätigt, als eine umfangreiche tryptische Spaltung des Leims nicht stattfindet. Sie bedarf aber insoweit einer Einschränkung, als eine geringe Leucinbildung stets nachweisbar ist. 